\title{
Living labs and vacancy in the neoliberal city
}

\author{
Paolo Cardullo*, Rob Kitchin, Cesare Di Feliciantonio
}

NIRSA, National University of Ireland Maynooth, County Kildare, Ireland

\begin{abstract}
A B S T R A C T
This paper evaluates smart city (SC) initiatives in the context of re-using vacant property, focusing on the role of living labs (LL). LL utilise Lo-Fi technologies to foster local digital innovation and support community-focused civic hacking, running various kinds of workshops and engaging with local citizens to co-create digital interventions and apps aimed at 'solving' local issues. Five approaches to LL are outlined and discussed in relation to vacancy and gentrification: pop-up initiatives, university-led activities, community organised venues/activities, citizen sensing and crowdsourcing, and tech-led regeneration initiatives. Notwithstanding the potential for generating temporary and independent spaces for transferring digital competences and increasing citizens' participation in the SC, we argue LL foster largely a form of participation framed within a model of civic stewardship for 'smart citizens'. While presented as horizontal, open, and participative, LL and civic hacking are rooted often in pragmatic and paternalistic discourses and practices related to the production of a creative economy and a technocratic version of SC. As such, by encouraging a particular kind of re-use of vacant space, LLs are used actively to bolster the Smart City discourse, as part of the more general neoliberalization of urban political economy. We discuss these approaches and issues generally, drawing on previous fieldwork and with respect to a case study of Dublin, Ireland.
\end{abstract}

\section{Introduction}

"Living Labs are defined as user-centred, open innovation ecosystems based on a systematic user co-creation approach integrating research and innovation processes in real life communities and settings. In practice, Living Labs place the citizen at the centre of innovation, and have thus shown the ability to better mould the opportunities offered by new ICT concepts and solutions to the specific needs and aspirations of local contexts, cultures, and creativity potentials. ${ }^{1 "}$

(European Network of Living Labs, ENOLL, our emphases).

The Living Lab (LL) concept is generally intended as a bottom-up approach to the smart city (SC), designed to increase citizens' participation and involvement in 'solving' local issues. LLs utilise Lo-Fi technologies to foster local digital innovation and support community-focused civic hacking, running various kinds of workshops and engaging with local citizens to co-create digital interventions and apps. They were born in the open design tradition of MIT's experimentation with space-aware technologies, fostering the idea that digital technologies should first be tested by their users' "in-vivo settings" (Dutilleul, Birrer, \& Mensink, 2010). LLs were given a primary role in the development of SC in 2006 when the European Commission decided to "put the user in the driver's seat" of the innovation process (EC 2009, cited in Dutilleul et al., 2010) and they are now at the forefront of SC strategies given their citizen-centric focus and appeal as the target of state and EU funding (Voytenko, McCormick, Evans, \& Schliwa, 2016). In other words, there has been a notable shift from passive user feedback to a more active approach based on users' involvement (co-creation or participatory design). Therefore, the LL approach situates the SC as a testbed for experimenting with the design and use of digital technologies in situ. Here, the SC is recast in two ways. First, as being a beta version in need of testing through trialling, where smart infrastructures are "white-boxed", layer by layer (Corsin Jimenez, 2014). Second, as being citizen-centric, a more open, affordable, and democratic endeavour, developed from the bottom-up around the needs and desires of local residents, with LL supplying the necessary skills and competences to citizens.

The promoters of LL highlight three important characteristics that enable such a vision of SC. Firstly, LLs are a context-based experience, which is difficult to replicate in the same way elsewhere (Clark \& Shelton, 2016; Voytenko et al., 2016). Secondly, LLs are temporality contingent, framed with respect to the temporal cycles of projects, technologies and funding, and often run the risk of shifting a focus away "from place-making to creating temporary events" (de

\footnotetext{
* Corresponding author.

E-mail address: paolo.cardullo@mu.ie (P. Cardullo).

${ }^{1}$ http://www.openlivinglabs.eu/aboutus.
} 
Lange \& de Waal, 2013). Thirdly, LLs are intended to operate as multistakeholder endeavours that include local residents, acting as a counterweight to the techno-centric, top-down approach to SC initially forwarded by big business. Ultimately, the ambition for some is that the SC will eventually boast a model of governance in which "a community assumes political and expert management over its infrastructures" (Corsin Jimenez, 2014).

We present five examples of LLs - pop-up events, university-led activities, community organised venues/activities, citizen sensing and crowdsourcing, and tech-led regeneration initiatives - discussing each in the context of addressing issues of urban vacancy at a time of neoliberal/austerity urbanism (Di Feliciantonio, 2016). Drawing on critical geographers' work, in fact, we consider cities as critical nodes in the complex scalar politics of "actually existing neoliberalism" (Brenner \& Theodore, 2002), where neoliberal programs have been "directly 'interiorized' into urban policy regimes" with "a 'shock treatment' of deregulation, privatization, liberalization and enhanced fiscal austerity." (Peck, Theodore, \& Brenner, 2009, p. 58) With the proliferation of unfinished and vacant buildings as a consequence of the global financial crisis, their reactivation has been one of the priorities of local governments in order to boost investments (Kitchin, Hearne, \& O'Callaghan, 2016; O'Callaghan \& Lawton, 2016). Because of their contingent nature and their emphasis on digital innovation and 'participation', LLs have been one of the preferred options to reactivate these spaces, offering the potential for the creation of independent (although temporary) spaces. However, just as the smart city agenda has been criticized for reproducing neoliberal rationality (e.g. Hollands, 2008; Vanolo, 2014), LLs based on vacant urban sites are at risk of being co-opted into the neoliberal model of city growth. We have summarized this interplay between potentials and limits of LL in Table 1, which represents a heuristic device for better evaluating LL initiatives with respect to vacancy, governance and city policy. Its categories are not exclusive - e.g., a crowdsourced project can enable forms of communal engagement and ownership of the data produced for anti-gentrification purposes, assuming citizens have the political capital to act upon the data. Neither are these categories unique to each typology of LL - e.g., different LL initiatives can be co-opted into the 'creative city' model of city growth, whether they are pop-up artistic projects or university-led experiments.

In the definition of LL quoted at the start of the paper, there is an evident slippage between the 'user-centric' model of LL and its assumed 'citizen-centric' nature. Which raises the question, what model of governance is operating with respect to our five different forms of LL? Are LL really promoting horizontal, open, and participatory SC or, rather, is their ethos rooted in pragmatic and paternalistic discourses that enact a form of civic stewardship for 'smart citizens'? Thus, we ask whether LLs really realise the bottom-up ethos of SC they promise, or rather they foreground an urban environment primed for the "creative classes" (see Castelnovo, Misuraca, \& Savoldelli, 2015; Clark \& Shelton, 2016; Florida, 2003)? In the next sections we start unravelling these links by first looking at urban vacancy in the post-crisis city. Then, we provide a systematic critical overview of five different typologies of LL in relation to city vacancy and urban governance. In the conclusion, we set up an agenda for future research around forms of smart citizens' participation and the SC discourse.

Our analysis is based on a patchwork of different approaches at different times by each of the authors: interviews with observation of many LL projects, hackathons, ${ }^{2}$ and social centres' activism in Dublin, London, and Modena; systematic desk-based research of secondary sources; and fieldwork concerning SC initiatives in Dublin as part of a large European funded project that involved more than three hundred interviews and participant observation by a number of team members,

${ }^{2}$ A hackers' marathon, usually lasting one day or a weekend, where programmers collaboratively code in an extreme manner.

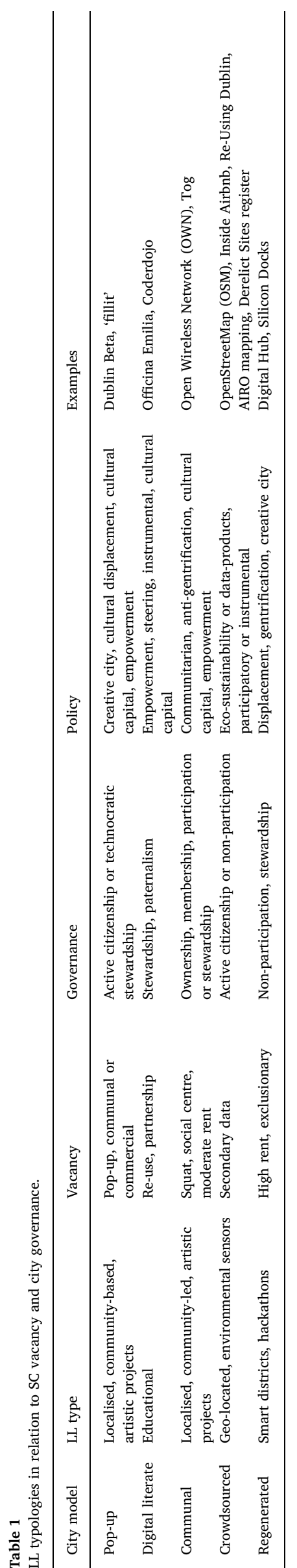


with many focusing on civic hacking, urban data commons, and the role of citizens in the smart city, though not the role of LL and vacancy directly. The paper focuses mostly on Dublin, a particularly suitable case to understand the connections between neoliberal urbanism, vacancy, LL and SC. In fact, following the enthusiastic embracement of neoliberal policies by the Irish government favouring the property-development sector and urban regeneration (MacLaren, Kelly, \& MacLaran, 2014) - policies which have been reinforced in the current phase of austerity (Mercille \& Murphy, 2015) - in the last decades the city property market has experienced an extremely dynamic cycle made of boom during the years of the 'Celtic Tiger', followed by a violent crash and then by a spectacular recovery concerning mainly offices and commercial spaces. However, as acknowledged by Dublin City Council strategic plans, ${ }^{3}$ urban vacancy remains widespread. According to Kitchin, O'Callaghan, Boyle, Gleeson, and Keaveney (2012) these "new ruins" were created through the search for a spatial fix by speculative capitalism that have come to symbolize the collapse of the 'Celtic Tiger' economy.

\section{The political economy of urban vacancy}

The definition of abandoned/vacant buildings varies from place to place and according to different parameters related to shifting power relations (Pearsall, Lucas, \& Lenhardt, 2014). Several contributions in critical political economy and urban studies have shown how the capitalist city needs vacant sites for its own reproduction (Harvey, 1978; Rutland, 2010; Smith, 1982). In fact, urban (political and financial) elites perceive and frame vacancies as an opportunity for "revalorization" and "redevelopment", although this usually ends by furthering inequalities and exclusion (Marcuse, 1985). Such long-standing tensions have been exacerbated by the rising of finance as the main driver of capital accumulation since land and real estate are particularly attractive as financial assets, because of the tension between the fixity/ immobility of land and real estate, and the volatility of financial capital amplifying market cycles (e.g., Beauregard, 1994; Gotham, 2009). Thus, urban policy is often oriented to leveraging investments in order to promote urban regeneration, and attract new users, residents and economic functions, rather than promoting social inclusion and redistribution.

With the increasing rate of vacant sites across different cities, temporary use for social and cultural purposes have been framed as the main response to city abandonment and a "low-cost" solution to promote urban regeneration and new investments (Bishop \& Williams, 2012). The rationale behind local institutions promoting temporary uses appears to reproduce the logic behind the boom of urban policies aimed at attracting the "creative class" - in line with the model introduced by Florida (2003); in fact, as argued by Peck (2005, p. 761), "city leaders (...) are embracing creativity strategies not as alternatives to extant market-consumption and property-led development strategies, but as low-cost, feel-good complements to them". In other words, urban gentrification and an entrepreneurial approach to urban development have been actively sought-after strategies of urban growth. These strategies include models of accumulation based on rent and property speculation, inward investment in advanced producer services and digital industries, and the courting of urban technocratic elites and their new forms of economy that were becoming "spatially fixed in cities in the postindustrial era" (Kitchin et al., 2012, p. 1313). Thus, the label "Smart City" suggests a model of IT- and communication-led city growth which enacts a form of entrepreneurial urbanism; the latest phase of this being the SC, its techno-scientific version (Hollands, 2008).

\footnotetext{
${ }^{3}$ See for instance the Dublin City Development Plan 2016-2022 which identifies more than 280 vacant sites (p. 45; the full document is available here: http:// dublincitydevelopmentplan.ie/).
}

The forms assumed by projects for temporary uses are variegated, from participatory planning projects to contentious initiatives linked to autonomous social movements. Different terminologies have been mobilized to account for this diverse set of initiatives intervening in urban space ('Do-It-Yourself', 'grassroots', 'insurgent' and 'guerrilla'), although scholars and policy-makers tend to refer to them as "tactical urbanism", regrouping "small-scale activities undertaken by local citizens that redesign their urban area to be more "liveable"' (Mould, 2014, p. 529). However, critics argue such a bottom-up ethos has been incorporated by neoliberal urban political agendas in search of "low-cost solutions" (Pratt \& Hutton, 2013) in times of "austerity urbanism" (Peck, 2012). The transformation of the city appears 'alternative' since it mobilizes mottos like "creativity" and "participation", while hiding a "business-as-usual" (profit-oriented) approach; therefore, the incorporation of these activities into mainstream urban policies has caused the loss of their subversive character, making them just another (commercial) label. Moreover, they reify the negative consequences of neoliberal urban politics: vacancy rates increase while access to urban properties' market remains prohibitive, an increasing number of people losing their houses or unable to find affordable locations for different scopes (working, social activities, etc.).

Although acknowledging the importance of vacancy in the housing sector, in this paper we focus on non-residential vacant buildings, offering a systematic typology of LL under neoliberal urbanism. Each traced category is related to a specific (set of) characteristic(s) of the political economy of vacant spaces in present times. "Pop-up urbanism" relates to the need to promote low-cost policies for urban renewal, valorizing the 'creativity' of different social actors, including contentious ones whose instances have been subsumed by urban elites (e.g., Mayer, 2013). The "digital literate city" builds upon Florida's model which prioritizes human capital and 'talent' as main drivers of urban economic growth. The "communal city" represents an autonomous response by different social actors for whom economic downturn opens new possibilities (e.g., Bresnihan \& Byrne, 2015). The "crowdsourced city" highlights the potentialities and limits of collective participation which can take different forms under neoliberal urban governance structures. Finally, the "regenerated city" shows how urban entrepreneurialism currently prioritizes digital technologies as a key driver for urban redevelopment projects, the main aim being to attract investments and 'smart' (and wealthy) residents.

\section{The pop-up city}

The notion of 'pop-up urbanism' has a relatively short history, linked to the recent disastrous earthquakes in Christchurch, New Zealand $(2010-11)$. Here, a group of non-for-profit organisations started re-building parts of the destroyed city using low-cost, gerryrigged solutions to create new spaces or reclaim damaged ones, usually for leisure and entertainment purposes but also for work. ${ }^{4}$ This approach to temporary space-making has, however, a longer tradition in: tactical urbanism for play-and-disruption - from the Situationist International since the 1950s (Bonnett, 2006) to more contemporary search for serendipity and discovery (Foth, 2016); DIY urbanism, where participants directly intervene in projects (Till \& McArdle, 2016); and hackable urbanism, in which urban space is not seen as given, but as moving elements that can be repurposed (Cardullo, 2014; Corsin Jimenez, 2014; de Lange \& de Waal, 2016). These temporary interventions in city space draw on community building, civic participation, artistic intervention, alternative media practices, and guerrilla urbanism. An example of a pop-up LL is the Fostering Digital Participation Project, which in 2015 set up mobile containers units that travelled

\footnotetext{
${ }^{4}$ http://sustainablecities.org.nz/2014/02/stories-of-urban-recovery-fromchristchurch/.
} 
across Australia. ${ }^{5}$ A Dublin City Council initiative, Dublin Beta has run a number of street-based pop-up initiatives working with citizens, though most are low- or no-digital tech in nature (such as pop-up parks and secure bike sheds in parking bays, new gutter run-off systems, painting street infrastructure to discourage vandalism) (Perng, 2017). Also in the city, a diverse range of pop-ups are being facilitated through a web platform, 'fillit', that aims to match vacancies and pop-up events: "for people looking for the perfect temporary venue for events, pop-ups, retail, promotions and everything in-between". 'fillit' displays a business model similar to AirBnB, but with a twist: if the vacancy is listed for free, 'fillit' does not charge a fee either, because it also aims at "inspiring theatre groups, youth centres, the arts or start-ups".

Most pop-up projects involve social media platforms as an interface between participant stakeholders, technology, and places. They work well with the spatio-temporal dimension of digital interactions, which involves fast, transitory, and sometimes ephemeral connections. In fact, as de Lange and de Waal (2013) suggest, pop-up LL projects embody a "shift from manipulating space to manipulating space in time". A key problem with the transitory character of a pop-up is thus its ontological nature: the vast majority of urban dwellers probably do not live, or want to live, in pop-up cities; neither might they want to dwell in temporary 'hybrid' locations, but in actually-serviced cities. In order to participate to pop-up LL, citizens are required to be pro-active, engaged, and ready to play in any up-and-coming event. Moreover, participant citizens are assumed to be already in possession of, or are willing to receive, the cultural and social capital necessary to enable them to participate. These are scarce currencies in modern urban living, more available to some people than others.

This paradox of digital inclusion and digital divide is sometimes made explicit in the SC literature. According to Castelnovo et al. (2015), SC offer a unique possibility for urban stakeholders for "co-design, codecision, co-production and co-evaluation". Moreover, SC are necessary in order to create "a climate suitable for an emerging creative class". Their "holistic" view on smart cities is here translated into a platform for the digitally-literate middle-class of urban creatives, social innovators and professionals. This view re-proposes Florida's assumption that cities need to change towards a flexible and 'urban cool' business model in order to attract the creative class (Florida, 2003; see Lawton, Murphy, \& Redmond, 2014). Pop-ups can, on the one hand, transform place to appeal to the generation of hipster millenials, with the likely cultural and exclusionary displacement effects on disadvantaged classes (see Marcuse, 1985). On the other hand, pop-ups can aid local artists, civic hackers and socially creative people who become stuck in the paradox of urban regeneration: "neither able to successfully collude due to art's lingering requirement for autonomy, nor to effectively opt out" (Slater \& Iles, 2009). In this context, it is relevant to mention that Dublin independent pop-up spaces - carved in the niches of the city rapid boom-and-bust housing policy of early 2000s (Kitchin et al., 2012) - are a recent tradition of eclectic and lively, but politically non-radical spaces (Bresnihan \& Byrne, 2015).

\section{The digitally literate city}

The second kind of LL that can occupy vacant property is a university-led Lab, a model of partnership with government and industry that is currently "blossoming" (Evans \& Karvonen, 2014). Typically this involves long-term educational activity with targeted groups, such as young people, students, and women. In the case of Dublin, Dublin City University has run coderdojo sessions since 2012, including coding, making, games development, and also runs specific sessions for girls. ${ }^{7}$ On its innovation campus, DCU has also partnered with TechShop, a

\footnotetext{
5 http://digitalparticipation.net.au/methodology/.

${ }^{6}$ https://www.fillit.ie/.

${ }^{7}$ http://coderdojodcu.com/.
}

"membership-based workshop and fabrication studio that provides access to machines, tools, software", and a "community of creative people, classes, workshops, instruction and meet-ups" for "digital and hardware innovators and entrepreneurs in Dublin". The innovation campus is a refurbished former vacant space that used to be occupied by a state agency, but is now university property.

Another example of university-led Lab was Officina Emilia (OE, Modena 2000-15), an action-research and museum-lab for the regeneration of competencies in mechanical industries. ${ }^{8}$ Its objective can be summarized as "linking science, technology, engineering, mathematics and social sciences in a more effective way through the design of relationships, tools, and innovative pilot actions" (Mengoli \& Russo, 2017). The Officina - which in the Italian Operaist tradition means 'sweatshop' - was connected with schools, teachers, and the SME sector, and its activity sometimes became part of local schools' curriculum. More importantly for the theme of this paper, OE was located in a vacant industrial warehouse in the middle of Modena's Artisan Village, a place and a city with a long tradition of working-class and co-operative presence. After 15 years of intense activity, OE and its Museum-Lab had to close due to a change in policy of its principal funding bodies. The timeline on which the $\mathrm{OE}$ cycle is set offers some space for analysis. During the last few years, in fact, Italy has been at the forefront of the SC discourse (Vanolo, 2014): in particular, the City and University of Bologna, capital of Emilia-Romagna, have devolved significant funding to SC initiatives that include 'the citizen'. In 2012-14, parallel to a large marketing campaign, the city re-launched the civic network Iperbole 2020 , focused on 'community needs'. ${ }^{9}$ It is bewildering that, in a climate in which City and University struggle to start-up smart inclusive projects, a well-established Lab for the regeneration of (digital) competences is closed. City vacancies can be a host of all sorts of interesting projects that boast community engagement and citizens' participation, but they depend upon political will and the creation of flexible institutional tools. However, the interface between different interests and diverse publics cannot be exclusively centred on digital technologies, social media, and open datasets (see McLaren \& Agyeman, 2015). These instruments greatly help communication, as well as influence placemaking and the organisation of "the city as a society" (de Waal, 2014). However, in the Neoliberal City the provision of free or affordable vacant premises can be crucial to the sustainability of inclusive LL projects. Needless to say, the pool of vacancies currently experienced by the City of Dublin can be a facilitator in this sense.

\section{The communal city}

LL initiatives are sometimes medium-term interventions in local neighbourhoods that echo the traditional ethos and organisation of community/social centres. This kind of LL usually rotates around wellknown members in a community of interest, who often act as 'benevolent dictators' in the various projects. These are civic hackers or community advocates who provide the stewardship necessary to connect people and possess strong technical skills with respect to building and maintaining networked hardware and software applications. This sort of LL, sometimes a hacker-space or art-space, is hosted in either vacant public or private space, but often seeks to maintain the characteristics of an "independent space": in both cases, rent can be a crucial factor for the sustainability of the project (Bresnihan \& Byrne, 2015). ${ }^{10}$ Typically, these LLs undertake a rolling set of projects that seek to address specific problems, such as Wi-Fi connectivity (Cardullo, 2017), civic apps (Perng \& Kitchin, 2016), or planning applications (de Lange \& de Waal, 2016). Examples of such initiatives in Dublin are Tog,

\footnotetext{
$\mathbf{8}$ http://www.officinaemilia.unimore.it/site/home/in-english.html.

9 http://iperbole2020.comune.bologna.it/smartcity/.

${ }^{10}$ The Dublin-based maker space TOG, for instance, charges a 45 Euro monthly membership fee, mostly to cover rent and utility bills: https://www.tog.ie/membership.
} 
a maker-space that includes digital projects, and Code for Ireland that meets monthly to develop civic apps, though it has no permanent space, its meet-ups migrating between the corporate offices of Google, Facebook and LinkedIn (see Perng \& Kitchin, 2016). We suggest that such forms of civic hacking, with medium-term investment in a specific community of interest, might have a limited or even negative effect towards gentrification and cultural displacement.

An example of this is the Open Wireless Network (OWN) in innercity London, where wireless communication was indeed of secondary importance to the locals who participated (Cardullo, 2017). More importantly, for years OWN contributed to community-building, local knowledge exchange, and some instances of anti-gentrification activism. The case study also suggests that to make 'community' operative requires a great deal of stewardship (time and funding for maintenance, management, and investment in cultural and social capitals), contradicting the notion that technology should be the automatic interface for bottom-up SC projects. Rather, civic hackers and enlightened professionals provide the 'magic' of community relations, influencing projects working and outcomes. This type of LL is in fact based on trust and social interfacing that is accrued over time. However, time seems to be structurally lacking in projects that rely on new media to tackle local issues (see de Lange \& de Waal, 2013). In other words, the transitory character of the 'event' around which community-based activities are mobilized (planning applications, civic hacking, or artistic projects) raises questions in terms of the long-term sustainability of community relations activated through LL strategy.

\section{The crowdsourced city}

A fourth type of LL concerns the gathering of meaningful data via smart sensors or via citizens' reporting. The urban landscape becomes the LL, with participants practising citizen science initiatives aimed at better understanding local conditions, or being enrolled as citizen sensors. Examples of such endeavours include Sensornet, ${ }^{11}$ which pooled together sensor data of air traffic noise in Amsterdam, and the TrackTrash project by MIT, ${ }^{12}$ that tracked the paths of trash deposited in New York. In these cases, citizens' participation is demanded for the installation of monitoring sensors, but the experiments do not require continuous active engagement: once installed, the sensor generates data regardless, though citizens may be involved in data analysis and acting upon the data. Alternatively, citizens may be enrolled as passive citizen sensors, for example, their smartphones being tracked across a city by a sensor network to better understand footfall and movement patterns. Here, the citizen is a data-point: governance is not so much around a territory, but "through enabling the connections and processes of everyday urban inhabitations within computational modalities" (Gabrys, 2014). In general, such data have little to do with vacancy, other than providing data on certain conditions within which vacant property resides.

In contrast, crowdsourcing projects are being used to identify vacant property, relying on users' inputs to generate pertinent data. Such forms of crowdsourcing usually work by piping data from Google Map or Open Street Map into a mobile app, with vacant units and associated details and photos being located on the map. A couple of different crowdsourced initiatives relating to vacancy have been undertaken in Dublin. The first was initiated by a small group who walked around the city, noted vacant units and uploaded them to a dedicated Google Maps page $^{13}$ (see also O'Mahony \& Rigney, 2016). This was then followed by Re-Using Dublin, ${ }^{14}$ in which users can explore vacant sites or add any

\footnotetext{
11 http://www.sensornet.nl/english/.

12 http://senseable.mit.edu/trashtrack.

${ }^{13}$ For an account see https://www.thejournal.ie/derelict-sites-in-dublin-get-mapped969180-Jun2013/.

14 http://www.reusingdublin.ie, which recently has been taken over by homelessness charity Fr. Peter McVery Trust and is more centrally focused on housing.
}

they have discovered. Other related sites include Inside Airbnb ${ }^{15}$ that details the properties that are not in permanent use but are let through Airbnb lettings, the AIRO mapping module ${ }^{16}$ on vacant housing identified in Census 2011, and Dublin City Council Derelict Sites register ${ }^{17}$ though these last examples are fixed and static sites, accessible to citizens, but not updatable by them. Somewhat ironically, one effect of crowdsourcing vacancy is to identify investment opportunities for gentrification. Another problem of crowdsourcing projects is maintaining contributors' motivation and enthusiasm, with the site often lapsing into a static and out-of-date service (Dodge \& Kitchin, 2013). Indeed, other cities have not managed to maintain the momentum of citizens' participation, with our searches for similar projects often leading to a "404 error" (page not found), or to "dataset not available" notices. $^{18}$

We would argue many of these 'citizen-centric' initiatives seem to act like a smokescreen around the SC: they are hyper-visible, compared to their actual impact and effective participation, and this can be attributed to the large social media presence these initiatives have. The reliance on project participants, the unsustainability of crowdsourcing initiatives and the failure of the city to display their own vacant properties bring us to the issue of governance. Who is responsible for urban vacancy? Who is controlling the SC? To what extent can citizens impact on how space is calculated and used? And once data are collected and analysed, who has the political capital to meaningfully act upon the data (see Gabrys, 2014)?

\section{The regenerated city}

For advocates of SC, one of the key reasons for developing and implementing SC initiatives is to help grow and sustain local economies through attracting foreign-direct investment and fostering start-ups and indigenous SMEs. The digital economy is seen as a key sector for generating new employment and SC initiatives, a means to attract talented workers and facilitate economic activity, as well as being a new market opportunity. Digital businesses need to locate in an ecosystem of suitable office buildings with high quality technical systems, a strong concentration of business and support services, and a pool of suitable labour. One way to create these conditions is to regenerate an existing city area, one that occupies a central site near to key transport links and other business services, repurposing or replacing existing buildings. Here, LLs are seen as central to an ongoing process of 'modernisation', achieved by extending pioneering small-scale projects, design-focused $\mathrm{LL}$, and an entrepreneurial culture of open innovation, to the overall organisation of urban space and living.

In the case of Dublin, there are a number of localised agglomerations of digital companies. Some of these have been built on greenfield sites on the edge of the city, such as Sandyford, Citywest, and Blanchardstown. In the city centre there are two key sites of agglomeration, both of which are regeneration initiatives, redeveloping old, largely vacant or former industrial sites: The Digital Hub and Silicon Docks. The former was established in 2003 and is managed by the Digital Hub Development Agency. ${ }^{19}$ It is located to the west of the city centre in the Liberties, an area of long-standing social deprivation. The Digital Hub itself is housed in eight former buildings of the Guinness factory site and supports circa 90 companies employing between them 800 to 1000 employees, as well as the NDRC, a state-backed early stage investor and accelerator for tech start-up companies. As companies grow, they leave to find their own premises to be replaced with new start-ups or SMEs (nearly 200 companies have been supported to date).

\footnotetext{
15 http://bit.ly/2lHzKNJ.

16 http://airo.maynoothuniversity.ie/mapping-resources/overview.

17 https://data.gov.ie/dataset/derelict-site-register.

${ }^{18}$ For example, this seems to be the case for the city of Bologna: http://dati.comune. bologna.it/immobili-inutilizzati.

19 https://www.thedigitalhub.com/.
} 
The Digital Hub is also a key agent in local regeneration, using a publicprivate partnership model to redevelop and invest in local property stock, including student accommodation, restoring Georgian buildings and other industrial and brownfield sites for office space. Its ambition is to develop a vibrant digitally-driven economy in the area, but part of its remit is also support the local community. To this end it has participated in what might be considered LL initiatives including a joint programme with the National College of Art and Design, located nearby, to teach local kids to be "future creators", working with local schools on the "connected classroom", and supporting community initiatives such as LAMP (Local Asset Mapping Project) concerning older people's health.

Silicon Docks ${ }^{20}$ is located to the east of the city centre around Grand Canal basin and the old Dublin docks on the northern and southern side of the River Liffey. The area was initially part of the strategic development zone overseen by Dublin Docklands Development Agency (DDDA), which operated from 1997 to May 2012. In late 2012 a smaller, revised Docklands SDZ (Strategic Development Zone) was created. While the original area included older, residential communities, the new Docklands SDZ's boundaries have been drawn to exclude such communities and, when completed, it is anticipated that it will include only 2300 residential units, most of them newly build, high-end apartments (O'Hara, 2015). The Docklands SDZ is already home to the European headquarters of many global IT companies including Google, Facebook and LinkedIn. It has also been recently designated a 'smart district', an area-based LL for trialling new SC technologies such as sensor networks, smart lighting, smart grids, etc. (Heaphy \& Pétercsák, 2016). Although dominated by large multinationals, the area is also home to numerous tech start-ups and incubator space such as Dogpatch Labs. Community-focused initiatives include Code for Ireland, though many of the participants are workers employed by companies in the area, rather than residents traditionally located nearby (that is, the participants are largely part of the gentrifying class).

In both cases, the primary focus is on growing the digital economy and regenerating the area into a vibrant economic zone. While there are some attempts to engage with local communities through LL initiatives, these are largely tokenistic to play out good corporate social responsibility, as opposed to creating a SC from the bottom-up. Rather than local communities fully benefiting from economic revitalisation, the creative class are being drawn into these new digital hubs displacing existing residents through soaring rental and property prices. As such, these areas are key active sites of gentrification where local authorities purposively seek gentrification as an ideal policy solution for urban change (Lawton \& Punch, 2014).

\section{Concluding remarks}

All of the LL interventions highlighted in this paper seek to address the pressing issue of citizens' engagement, participation, and control in the SC. de Lange and de Waal (2013) go further, suggesting the LL approach can foster city "ownership", that is, in their own words, "an inclusive form of engagement, responsibility and stewardship" of "what belongs to us all". Stewardship can be seen as an ethics that implies planning and managing resources on behalf of all citizens. It can be enacted by a body on behalf of people - such as a city council, a LL, or a development agency - or be enacted collectively by those people themselves. However, what is seen as a desirable outcome is contested across groups. Stewardship enacted on behalf of others can easily slip into civic paternalism; that is, elites deciding what is best for citizens. The question with respect to LL is whether the different forms outlined above work to create a bottom-up, citizen-led, participatory and

${ }^{20}$ This is the colloquial name for the area, first used by the media in 2011 to refer to the concentration of high tech companies around an old canal basin, riffing on the notion of a concentrated, Irish version of 'Silicon Valley'. inclusive smart city - repurposing vacant property and digital technologies to the benefit of local communities - or ultimately work to serve the interests of capital and reinforce a model of technocratic governance by attracting middle-class creative and mobile workers? In this respect LLs appear to feature all the main contradictions shaping social processes (including contentious ones) under neoliberalism.

In this paper we have examined some LL initiatives which are small in scale and scope, transitory in time, and generally suitable for the creation of alternative spaces in which citizens' digital rights are fostered and enhanced. As grassroots experimentations with digital technologies, DIY urbanism, and participatory planning, some LL initiatives meet urban vacancies both in space and time, creating a patchwork of interventions in complex ecologies of city change; in fact, because of their contingent nature, LLs find in urban vacant spaces their main location, offering the possibility to experiment different forms of participation and engagement. The case study of the "communal city" offered some good practice, sometimes able to build trust in participants and, due to their long-standing investment, also transfer forms of capital necessary to enable participation from a variety of local people. Usually, these projects hinge around well-known community advocates or ethical hackers; a place easy to identify within a neighbourhood, such as a social/cultural centre; and activities that enhance the usevalue of a resource in meaningful ways, that is, they are deemed 'useful' because participants are able to share in commons (such as, the ownership and co-production of a wireless network).

However, in line with the debate around the political economy of urban vacancy, each approach suggested in the paper presents the risk, to various degrees, of being co-opted into the 'creative economy' discourse and urban entrepreneurialism, reproducing and reinforcing the neoliberalization of urban policies and space. This is particularly the case in urban regeneration-linked LL, where the initiatives are largely tokenistic and the ambition is to transform the area into a vibrant digital economy. As noted above, LL can contribute to the creation of "smart enclaves" (Clark \& Shelton, 2016), "cultural quarters" (Lawton \& Punch, 2014), and to direct, exclusionary, and cultural forms of displacement (Lawton et al., 2014; Marcuse, 1985) by attracting pools of users and initiators who are themselves active buyers in the inflationary property market of neoliberal cities. Whereas the SC discourse is fairly recent, over forty years of gentrification research have laid the ground for understanding the dynamics of capitalist urban development, and for unpacking different forms of displacement. While LL initiatives seem to work well with a rather limited temporal horizon, the enduring effects of gentrification are longer term. The paths through which LL initiatives are set within the SC debate raise questions, and the need for longitudinal research, around the risks for modelling urban space in a certain way.

Moreover, we argue that participation and citizen-engagement within LL initiatives are often fairly limited, organised and run within a technocratic ideal of governance which implies stewardship and civic paternalist frames. Being citizen-led or citizen-engaged in the SC does not necessarily confer notions of citizenship or rights to the digital city, or guarantee new digital urban commons. The development and use of participative SC software interfaces seem, in fact, to produce an 'ideal citizen' that willingly subscribes to the idea(l)s of technological solutionism promoted by SC discourses and acquires the cultural capital necessary to communicate or tinker with smart technologies. While often worthy and much more preferable to top-down forms of governance, it is unlikely that LL can fulfill 'citizen-centric' SC goals, without these being explicitly rooted in notions of citizenship and community-ownership, rather than citizen-participation and civic paternalism. The root to this, it seems to us, is within a communal city model of citizen engagement.

\section{Acknowledgements}

This paper was prepared for the workshop, 'The New Urban Ruins: Vacancy and the Post-Crisis City', 1-3 March 2017, Trinity College 
Dublin. The research funding for the paper was provided by a European Research Council Advanced Investigator Award, 'The Programmable City' (ERC-2012-AdG-323636).

\section{References}

Beauregard, R. A. (1994). Capital switching and the built environment: United States, 1970-89. Environment and Planning A, 26(5), 715-732.

Bishop, P., \& Williams, L. (2012). The temporary city. London: Routledge.

Bonnett, A. (2006). The nostalgias of situationist subversion. Theory, Culture \& Society, 23(5), 23-48. http://dx.doi.org/10.1177/0263276406067096.

Brenner, N., \& Theodore, N. (2002). Cities and the geographies of "actually existing neoliberalism". Antipode, 34(3), 349-379.

Bresnihan, P., \& Byrne, M. (2015). Escape into the city: Everyday practices of commoning and the production of urban space in Dublin. Antipode, 47(1), 36-55.

Cardullo, P. (2014). Sniffing the city: Issues of surveillance in inner city London. Visua Studies, 29(3), 285-293. http://dx.doi.org/10.1080/1472586X.2014.941550.

Cardullo, P. (2017). Gentrification in the mesh? City, O(0), 1-15. http://dx.doi.org/10. $1080 / 13604813.2017 .1325236$.

Castelnovo, W., Misuraca, G., \& Savoldelli, A. (2015). Citizen's engagement and value coproduction in smart and sustainable cities. International conference on public policy (pp. 1-16). . Retrieved from http://www.icpublicpolicy.org/conference/file/ reponse/1433973333.pdf.

Clark, J., \& Shelton, T. (2016). Technocratic values and uneven development in the "Smart City". Metropolitics. Retrieved from http://www.metropolitiques.eu/ Technocratic-Values-and-Uneven.html.

Corsin Jimenez, A. (2014). The right to infrastructure: A prototype for open source urbanism. Environment and Planning D: Society and Space, 32(2), 342-362. http://dx.doi. org $/ 10.1068 / d 13077 p$.

Di Feliciantonio, C. (2016). The reactions of neighbourhoods to the eviction of squatters in Rome: An account of the making of precarious investor subjects. European Urban and Regional Studies. http://dx.doi.org/10.1177/0969776416662110.

Dodge, M., \& Kitchin, R. (2013). Crowdsourced cartography: Mapping experience and knowledge. Environment and Planning A, 45(1), 19-36. http://dx.doi.org/10.1068/ a44484.

Dutilleul, B., Birrer, F. A., \& Mensink, W. (2010). Unpacking European living labs: Analysing innovation's social dimensions. Central European Journal of Public Policy, 4(1), 60-85.

Evans, J., \& Karvonen, A. (2014). Give me a laboratory and I will lower your carbon footprint!' - Urban laboratories and the governance of low-carbon futures in Manchester. International Journal of Urban and Regional Research, 38(2), 413-430. http://dx.doi.org/10.1111/1468-2427.12077.

Florida, R. L. (2003). The rise of the creative class: And how it's transforming work, leisure, community and everyday life. North Melbourne, Vic: Pluto Press.

Foth, M. (2016). Why we should design smart cities for getting lost. Retrieved from http://theconversation.com/why-we-should-design-smart-cities-for-getting-lost56492

Gabrys, J. (2014). Programming environments: Environmentality and citizen sensing in the smart city. Environment and Planning D: Society and Space, 32(1), 30-48. http://dx. doi.org/10.1068/d16812.

Gotham, K. F. (2009). Creating liquidity out of spatial fixity: The secondary circuit of capital and the subprime mortgage crisis. International Journal of Urban and Regional Research, 33(2), 355-371. http://dx.doi.org/10.1111/j.1468-2427.2009.00874.x.

Harvey, D. (1978). The urban process under capitalism: A framework for analysis. International Journal of Urban and Regional Research, 2(1-4), 101-131.

Heaphy, L., \& Pétercsák, R. (2016). Building smart city partnerships in the 'Silicon Docks'. Presented at the Creating Smart Cities workshop. Ireland: Maynooth University. Retrieved from http://bit.ly/2mjmyfd.

Hollands, R. G. (2008). Will the real smart city please stand up? Intelligent, progressive or entrepreneurial? City, 12(3), 303-320.

Kitchin, R., Hearne, R., \& O'Callaghan, C. (2016). Housing. In W. K. Roche, P. J. O'Connell, \& A. Prothero (Eds.). Austerity and recovery in Ireland: Europe's poster child and the great recession. Oxford University Press.

Kitchin, R., O'Callaghan, C., Boyle, M., Gleeson, J., \& Keaveney, K. (2012). Placing neoliberalism: The rise and fall of Ireland's Celtic Tiger. Environment and Planning A, 44(6), 1302-1326. http://dx.doi.org/10.1068/a44349.

de Lange, M., \& de Waal, M. (2013). Owning the city: New media and citizen engagement in urban design. First Monday, 18(11), Retrieved from http://firstmonday.org/ojs/ index.php/fm/article/view/4954.

de Lange, M., \& de Waal, M. (2016). Hacking Buiksloterham. Retrieved from http:// thehackablecity.nl/.

Lawton, P., Murphy, E., \& Redmond, D. (2014). Neoliberalising the City 'creative-class' style. In A. MacLaran, \& S. Kelly (Eds.). Neoliberal urban policy and the transformation of the city (pp. 189-202). UK: Palgrave Macmillan. http://dx.doi.org/10.1057/ 978113737705012.

Lawton, P., \& Punch, M. (2014). Urban governance and the 'European City': Ideals and realities in Dublin, Ireland: 'European city' ideals and realities in Dublin. International Journal of Urban and Regional Research, 38(3), 864-885. http://dx.doi.org/10.1111/ 1468-2427.12152.

MacLaren, A., Kelly, S., \& MacLaran, A. (2014). Neoliberal urban policy and the transformation of the city: Reshaping Dublin. Springer.

Marcuse, P. (1985). Gentrification, abandonment, and displacement: Connections, causes, and policy responses in New York City. Washington University Journal of Urban and Contemporary Law, 28, 195-240.

Mayer, M. (2013). First world urban activism: Beyond austerity urbanism and creative city politics. City, 17(1), 5-19.

McLaren, D., \& Agyeman, J. (2015). Sharing cities: A case for truly smart and sustainable cities. MIT Press.

Mengoli, P., \& Russo, M. (2017). A hybrid space to support the regeneration of competences for re-industrialization, working paper.

Mercille, J., \& Murphy, E. (2015). Deepening neoliberalism, austerity, and crisis: Europe's treasure Ireland. Springer.

Mould, O. (2014). Tactical urbanism: The new vernacular of the creative city. Geography Compass, 8(8), 529-539.

O'Callaghan, C., \& Lawton, P. (2016). Temporary solutions? Vacant space policy and strategies for re-use in Dublin. Irish Geography, 48(1), 69-87. http://dx.doi.org/10. 2014/igj.v48i1.526.

O'Hara, R. (2015). Communities locked out of Docklands future. Retrieved from http:// www.lookleftonline.org/2015/04/communities-locked-out-of-docklands-future/.

O'Mahony, E., \& Rigney, S. (2016). "What's the story buddleia?": A public geography of dereliction in Dublin City. Irish Geography, 48(1), 88-99.

Pearsall, H., Lucas, S., \& Lenhardt, J. (2014). The contested nature of vacant land in Philadelphia and approaches for resolving competing objectives for redevelopment. Cities, 40, 163-174.

Peck, J. (2005). Struggling with the creative class. International Journal of Urban and Regional Research, 29(4), 740-770.

Peck, J. (2012). Austerity urbanism: American cities under extreme economy. City, 16(6), 626-655. http://dx.doi.org/10.1080/13604813.2012.734071.

Peck, J., Theodore, N., \& Brenner, N. (2009). Neoliberal urbanism: Models, moments, mutations. SAIS Review of International Affairs, 29(1), 49-66.

Perng, S.-Y. (2017). Practices and politics of collaborative urban infrastructuring: Traffic light box artworks in Dublin streets. The programmable city working paper 33http://dx. doi.org/10.17605/OSF.IO/2XPQ7.

Perng, S.-Y., \& Kitchin, R. (2016). Solutions and frictions in civic hacking: Collaboratively designing and building wait time predictions for an immigration office. Social \& Cultural Geography, 1-20. http://dx.doi.org/10.1080/14649365.2016. 1247193.

Pratt, A. C., \& Hutton, T. A. (2013). Reconceptualising the relationship between the creative economy and the city: Learning from the financial crisis. Cities, 33, 86-95.

Rutland, T. (2010). The financialization of urban redevelopment. Geography Compass, 4(8), 1167-1178.

Slater, J., \& Iles, A. (2009, November). No room to move: Radical art and the regenerate city. Retrieved from http://tiny.cc/b50ogy.

Smith, N. (1982). Gentrification and uneven development. Economic Geography, 58(2), 139-155.

Till, K., \& McArdle, R. (2016). The Improvisional City: Valuing urbanity beyond the chimera of permanence. Irish Geography, 48(1), 37-68. http://dx.doi.org/10.2014/ igj.v48i1.525.

Vanolo, A. (2014). Smart mentality: The Smart City as disciplinary strategy. Urban Studies, 51(5), 883-899. http://dx.doi.org/10.1177/0042098013494427.

Voytenko, Y., McCormick, K., Evans, J., \& Schliwa, G. (2016). Urban living labs for sustainability and low carbon cities in Europe: Towards a research agenda. Journal of Cleaner Production, 123, 45-54. http://dx.doi.org/10.1016/j.jclepro.2015.08.053.

de Waal, M. (2014). The city as interface: How digital media are changing the city. Rotterdam: nai010 publishers. 